\title{
Preclinical Evaluation of Mesothelin-Specific Ligands for SPECT Imaging of Triple-Negative Breast Cancer
}

\author{
Christopher Montemagno ${ }^{1}$, Sandrine Bacot ${ }^{1}$, Mitra Ahmadi ${ }^{1}$, Brigitte Kerfelec ${ }^{2}$, Daniel Baty ${ }^{2}$, Marlene Debiossat $^{1}$, \\ Audrey Soubies ${ }^{1}$, Pascale Perret ${ }^{1}$, Laurent Riou ${ }^{1}$, Daniel Fagret ${ }^{1}$, Alexis Broisat*1, and Catherine Ghezzi*1 \\ ${ }^{1}$ Université Grenoble Alpes, INSERM, CHU Grenoble Alpes, LRB, Grenoble, France; and ${ }^{2}$ Aix Marseille Université, CNRS, INSERM, \\ Institut Paoli-Calmettes, CRCM, Marseille, France
}

\begin{abstract}
Mesothelin is a cell-surface glycoprotein restricted to mesothelial cells overexpressed in several types of cancer, including triplenegative breast cancer not responding to trastuzumab or hormonebased therapies. Mesothelin-targeting therapies are currently being developed. However, the identification of patients potentially eligible for such a therapeutic strategy remains challenging. The objective of this study was to perform the radiolabeling and preclinical evaluation

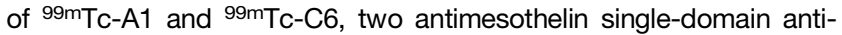
body (sdAb)-derived imaging agents. Methods: A1 and C6 were radiolabeled with ${ }^{99 \mathrm{mTc}}$ and evaluated in vitro on recombinant protein and cells, as well as in vivo in xenograft mouse models of the triplenegative breast cancer cell lines HCC70 (mesothelin-positive) and MDA-MB-231 (mesothelin-negative). Results: Both ${ }^{99 m T C}-A 1$ and 99mTc-C6 bound mesothelin with high affinity in vitro, with ${ }^{99 m} \mathrm{Tc}-\mathrm{A} 1$ affinity being 2.4-fold higher than that of ${ }^{99 \mathrm{mTc}-\mathrm{C} 6}$ (dissociation constant, $43.9 \pm 4.0$ vs. $107 \pm 16 \mathrm{nM}, P<0.05$ ). ${ }^{99 \mathrm{mT}} \mathrm{Tc}-\mathrm{A} 1$ and ${ }^{99 \mathrm{mTc}-\mathrm{C} 6}$ remained stable in vivo in murine blood $(>80 \%$ at $2 \mathrm{~h}$ ) and ex vivo in human blood ( $>90 \%$ at 6 h). In vivo ${ }^{99 m T c-A 1}$ uptake (percentage injected dose) in HCC70 tumors was 5-fold higher than in MDAMB-231 tumors and 1.5-fold higher than that of 99mTc-C6 $(2.34 \% \pm$ $0.36 \%$ vs. $0.48 \% \pm 0.18 \%$ and $1.56 \% \pm 0.43 \%$, respectively, $P<$ 0.01 ) and resulted in elevated tumor-to-background ratios. In vivo competition experiments demonstrated the specificity of ${ }^{99 m \mathrm{mc}-\mathrm{A} 1}$ uptake in HCC70 tumors. Conclusion: Mesothelin-positive tumors were successfully identified by SPECT using ${ }^{99 m T c-A 1}$ and ${ }^{99 m T c-}$ C6. Considering its superior characteristics, ${ }^{99 \mathrm{mT}} \mathrm{T}-\mathrm{A} 1$ was selected as the most suitable tool for further clinical translation.
\end{abstract}

Key Words: TNBC; mesothelin; nuclear imaging; SPECT

J Nucl Med 2018; 59:1056-1062

DOI: 10.2967/jnumed.117.203489

$\mathbf{T}$ riple-negative breast cancer (TNBC) is an invasive carcinoma that lacks expression of estrogen receptor, human epidermal growth factor receptor 2, and progesterone receptor. About $10 \%-$ $20 \%$ of breast cancer cases are found to be TNBC. Patients with TNBC have an aggressive clinical course, with a high recurrence rate and a short survival outcome (I). TNBC lacks effective targeted

Received Oct. 11, 2017; revision accepted Nov. 28, 2017.

For correspondence or reprints contact: Alexis Broisat, Laboratoire "Radiopharmaceutiques Biocliniques," INSERM UMR S 1039, Faculté de Médecine de Grenoble, Domaine de la Merci, 38700 La Tronche, France. E-mail: alexis.broisat@inserm.fr

${ }^{*}$ Contributed equally to this work.

Published online Mar. 23, 2018.

COPYRIGHT (C 2018 by the Society of Nuclear Medicine and Molecular Imaging. therapies, and efforts are focused on the identification of new potential targets such as the cell-surface glycoprotein mesothelin $(2,3)$. The mesothelin gene encodes a precursor protein of $71 \mathrm{kDa}$, processed into a shed form (megakaryocyte-potentiating factor) and a 40-kDa glycosylphosphatidylinisotol-anchored membrane protein, mesothelin (4). Mesothelin constitutive expression is restricted to mesothelial cells lining the pericardium, peritoneum, and pleura. However, mesothelin overexpression has been observed in $100 \%$ of epithelial mesotheliomas, most pancreatic and ovarian adenocarcinomas, and 34\%-67\% of TNBCs (5-7). Its biologic function is still poorly understood, and no detectable abnormalities have been observed in mesothelin-deficient mice (8). However, in pathologic conditions, several studies have recently indicated a potential role for mesothelin in cell survival, cell proliferation, tumor progression, and chemoresistance (9). Mesothelin expression has been correlated with a poorer patient outcome in several types of human cancer $(10,11)$, and mesothelin is associated with lymph node tumoral infiltration and a decreased overall survival in breast cancer (12). Among patients with TNBC, those with a mesothelin-positive tumor were found to develop more distant metastases and to have lower overall and disease-free survival (13).

The limited expression of mesothelin in normal human tissues and its overexpression in several types of aggressive human cancer make it an attractive candidate for therapy, including for TNBC $(7,14)$. Therefore, mesothelin-targeted therapies are currently undergoing clinical trials (15). In this setting, the identification of patients who could benefit from these targeted therapies remains challenging: an elevation of serum mesothelin has been shown in patients with mesothelioma and ovarian cancer but not in pancreatic cancer despite an overexpression of the membrane-bound mesothelin in these tumors $(16,17)$. Moreover, because of interand intratumor heterogeneity, tumor phenotype cannot be accurately assessed by biopsy. Nuclear imaging is a highly sensitive noninvasive imaging modality that might address this challenge. Prantner et al. developed and performed the in vitro characterization of two antimesothelin single-domain antibodies (sdAbs), A1 and C6, with high specificities and nanomolar affinities for the 40$\mathrm{kDa}$ mesothelin form (18). In the present study, in vitro and in vivo investigations were performed after ${ }^{99 \mathrm{~m}} \mathrm{Tc}$ labeling of these sdAbs ${ }^{99 \mathrm{~m}} \mathrm{Tc}-\mathrm{A} 1$ and $\left.{ }^{99 \mathrm{~m}} \mathrm{Tc}-\mathrm{C} 6\right)$ to evaluate their potential as imaging probes for the nuclear imaging of mesothelin-positive TNBC.

\section{MATERIALS AND METHODS}

\section{Cell Lines and Culture Conditions}

The HCC70 cell line was cultured using RPMI 1640 medium supplemented with $10 \%$ fetal bovine serum and $1 \%$ penicillin-streptomycin. 
MDA-MB-231 cells were cultured with Dulbecco modified Eagle medium supplemented with $10 \%$ fetal bovine serum and $1 \%$ penicillinstreptomycin.

\section{Western Blot Analysis}

Total proteins from HCC70 and MDA-MB-231 cells were extracted with radioimmunoprecipitation assay buffer. Proteins were separated by $4 \%-15 \%$ denaturing sodium dodecyl sulfate polyacrylamide gel electrophoresis and transferred onto a nitrocellulose membrane. The membrane was incubated with the antimesothelin antibody (Boster immunoleader). Actin was detected with anti- $\beta$-actin antibody (Beckton Dickinson). Revelation was assessed using the chemiluminescence enhanced chemiluminescence kit (Biorad).

\section{Production and Purification of sdAbs}

Production and purification of the anti-mesothelin sdAbs were done as previously published (18).

\section{Radiolabeling with ${ }^{99 m} \mathrm{Tc}$}

A heating step was necessary over the course of the radiolabeling procedure. Thermal unfolding of A1 or C6 was therefore monitored by circular dichroism. A1, C6, and an irrelevant control sdAb were then radiolabeled with ${ }^{99 \mathrm{~m}} \mathrm{Tc}$ using the tricarbonyl method and the C-terminal hexahistidine-tag as previously described (19). The radiochemical purity of all 3 sdAbs was determined immediately after labeling and $6 \mathrm{~h}$ after labeling by radio-high-performance liquid chromatography (Shimadzu).

\section{Lipophilicity}

The lipophilicity of ${ }^{99 \mathrm{~m}} \mathrm{Tc}-\mathrm{A} 1$ and ${ }^{99 \mathrm{~m}} \mathrm{Tc}-\mathrm{C} 6$ was evaluated using an octanol phosphate-buffered saline (PBS) distribution study. The partition coefficient $(\log P)$ was calculated as the radioactivity ratio of the organic phase to the aqueous phase using the following formula: $\log P=\log$ (total counts in 1-octanol/total counts in PBS buffer).

\section{Distribution and Stability in Murine and Human Blood}

The distribution and stability of ${ }^{99 \mathrm{~m}} \mathrm{Tc}$-sdAbs were evaluated after in vitro incubation in human blood and after in vivo injection into mice. A blood sample was centrifuged $(4,000 \mathrm{~g}, 2 \mathrm{~min})$ at the selected time points to separate the plasma from the blood cells. Trichloroacetic acid $(10 \%, 5 \mu \mathrm{L})$ was then added to the plasma fraction and the sample was centrifuged at $11,000 \mathrm{~g}$ for $3 \mathrm{~min}$ to separate large proteins $(>>15 \mathrm{kD})$ from the remaining plasma. Blood distribution was expressed as a percentage of total blood tracer activity contained in blood cells, large proteins, and remaining plasma fractions. To determine the stability of each radiolabeled $\mathrm{sdAb}$, the plasma fraction was analyzed using radio-high-performance liquid chromatography.

\section{Saturation Binding Experiments}

Saturation binding was determined on 96-well plates coated with human mesothelin recombinant protein (100 ng/well; R\&D Systems) or formalin-fixed HCC70 or MDA-MB-231 cells $\left(1.5 \times 10^{5}\right.$ cells/ well). Serial dilutions of ${ }^{99 \mathrm{~m} T c-A} 1$ and ${ }^{99 \mathrm{~m} T c-C 6}$ were incubated for $1 \mathrm{~h}$ at room temperature before being washed 5 times with PBSpolysorbate $0.1 \%$. The radioactivity in each well was then determined using a $\gamma$-counter (Wizard ${ }^{2}$; Perkin Elmer) and corrected for unspecific binding. ${ }^{99 \mathrm{~m}} \mathrm{Tc}-\mathrm{A} 1$ and ${ }^{99 \mathrm{~m}} \mathrm{Tc}-\mathrm{C} 6$ binding curves were fitted using a nonlinear regression equation (specific binding: $y=$ $\mathrm{B}_{\max } \times x /\left(\mathrm{K}_{\mathrm{D}}+x\right)$, with $x$ being the radioligand concentration, $\mathrm{K}_{\mathrm{D}}$ being the dissociation constant, and $\mathrm{B}_{\max }$ being the maximum number of binding sites, or receptor density) (GraphPad Prism, version 6, software), to determine $K_{D}$ values. Uptake was normalized to $B_{\max }$ for graphic representation of 3 independent experiments.

\section{In Vitro Competition Studies}

HCC70 and MDA-MB-231 cells $(200,000)$ were rinsed with PBS, detached using $5 \mathrm{mM}$ ethylenediaminetetraacetic acid, and incubated with ${ }^{99 \mathrm{~m}} \mathrm{Tc}-\mathrm{A} 1$ or ${ }^{99 \mathrm{~m}} \mathrm{Tc}-\mathrm{C} 6$ at their respective $\mathrm{K}_{\mathrm{D}}$ for $1 \mathrm{~h}$ at $4{ }^{\circ} \mathrm{C}$ in the absence or presence of a 200-fold excess of unlabeled A1 or C6, respectively. After 5 washes in cold PBS, the radioactivity was determined using a Wizard ${ }^{2} \gamma$-counter.

\section{Tumor Model}

All procedures performed were in accordance with the institutional guidelines and approved by the animal care and use committees of Grenoble University. To evaluate ${ }^{99 \mathrm{~m}} \mathrm{Tc}-\mathrm{A} 1$ and ${ }^{99 \mathrm{~m}} \mathrm{Tc}-\mathrm{C} 6$ biodistribution and tumor uptake, female BALB/c $n u / n u$ mice ( 5 wk old) were subcutaneously inoculated into the flank with either HCC70 cells $\left(3.5 \times 10^{6}, n=32\right)$ or MDA-MB-231 cells $\left(2 \times 10^{6}, n=6\right)$, in 2:1 (v/v) PBS/Matrigel (Corning). The tumors were allowed to grow for 3-4 wk to reach about $400 \mathrm{~mm}^{3}$.

\section{SPECT/CT Imaging}

The mice were divided into 4 groups: HCC70 tumor-bearing mice injected with either ${ }^{99 \mathrm{~m}} \mathrm{Tc}-\mathrm{A} 1$ (HCC70-A1, $n=8$ ), ${ }^{99 \mathrm{~m} T \mathrm{Tc}-\mathrm{C} 6}$ (HCC70-C6, $n=7$ ), or irrelevant ${ }^{99 \mathrm{~m} T c-C T L}$ (HCC70-CTL, $n=$ 7 ), and MDA-MB-231 tumor-bearing mice injected with ${ }^{99 \mathrm{~m} T c-A 1}$ (MDA-MB-231, $n=6$ ). SPECT/CT acquisitions were performed $1 \mathrm{~h}$ after intravenous injection of $49.1 \pm 13.7 \mathrm{MBq}$ of ${ }^{99 \mathrm{~m}} \mathrm{Tc}$-sdAbs. For competition studies, HCC70 tumor-bearing mice were injected with $17.6 \pm 5.3 \mathrm{MBq}$ of ${ }^{99 \mathrm{~m}} \mathrm{Tc}-\mathrm{A} 1$ with or without a 150 -fold excess of unlabeled $\mathrm{A} 1 \operatorname{sdAb}(n=5$ per condition). SPECT/CT acquisitions were performed using a dedicated system (nanoSPECT/CT; Mediso). Images were quantified after correction for decay and normalization to the injected dose. SPECT quantification was performed on the basis of the CT data, with the volume of interest corresponding to a sphere of $50 \mathrm{~mm}^{3}$ drawn at the center of the tumor on the CT image. ${ }^{99 \mathrm{~m}} \mathrm{Tc}-\mathrm{sdAb}$ uptake was expressed as percentage injected dose $(\% \mathrm{ID}) / \mathrm{cm}^{3}$.

\section{Postmortem Analysis}

Two hours after injection and immediately after the SPECT/CT image acquisition, the anesthetized mice were euthanized using $\mathrm{CO}_{2}$ and tumors were harvested along with other organs. Tissues were weighed, and tracer activity was determined with a Wizard ${ }^{2} \gamma$-counter. The results were corrected for decay, injected dose, and organ weight and were expressed as \%ID/g. Tumor-to-muscle (T/M) and tumor-to-blood (T/B) activity ratios were computed. Immunohistochemistry was performed on tumor slices using A1 sdAb $(20 \mu \mathrm{g} / \mathrm{mL})$ or a commercial antimesothelin antibody $(0.5 \mu \mathrm{g} / \mathrm{mL}$; Boster immunoleader $)$.

\section{Statistics}

Data were expressed as mean $\pm \mathrm{SD}$ and were compared using an unpaired Mann-Whitney test for intergroup analysis. The significance of linear correlations was assessed with a Pearson test. $P$ values lower than 0.05 were considered significant.

\section{RESULTS}

\section{9mTc Radiolabeling and Lipophilicity}

No thermal unfolding was detected by circular dichroism up to $65^{\circ} \mathrm{C}$ (Supplemental Fig. 1 [available at http://jnm.snmjournals. org]). This temperature was therefore used for the radiolabeling procedure. A1 and C6 were successfully radiolabeled with ${ }^{99 \mathrm{~m}} \mathrm{Tc}$. The radiochemical purity was higher than $99 \%$ immediately after radiolabeling, with a 16.1 - and 16.0-min retention time for ${ }^{99 \mathrm{~m}} \mathrm{Tc}-$ $\mathrm{A} 1$ and ${ }^{99 \mathrm{~m} T c-C 6}$, respectively (Figs. $1 \mathrm{~A}$ and $1 \mathrm{~B}$ ). Moreover, ${ }^{99 \mathrm{~m} T c-A} 1$ and ${ }^{99 \mathrm{~m} T c-C 6}$ remained stable for $6 \mathrm{~h}$ after labeling, with a radiochemical purity higher than $98 \%$. Log $P$ values were 


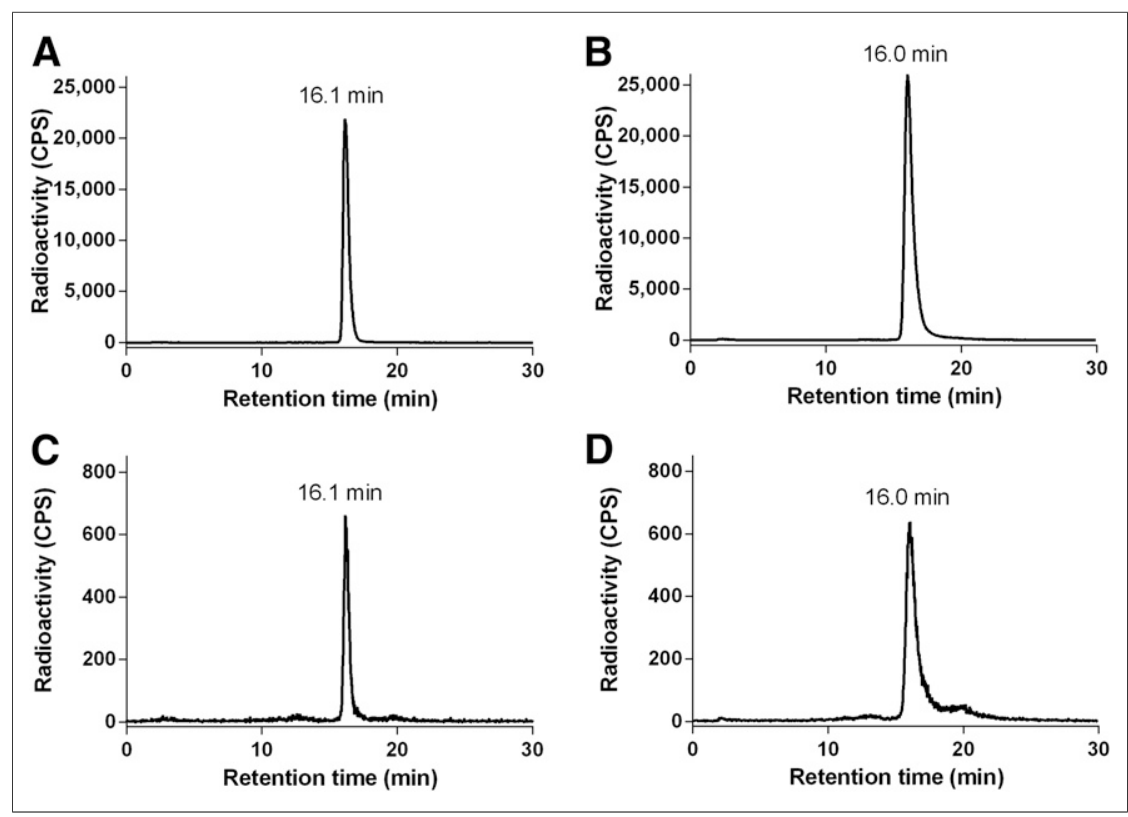

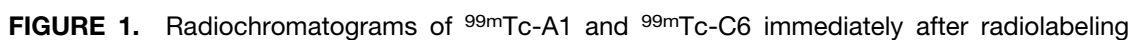
( $A$ and $B$, respectively) and $2 \mathrm{~h}$ after injection into mice ( $C$ and $D$, respectively). mesothelin was more than 2-fold higher than that of ${ }^{99 \mathrm{~m}} \mathrm{Tc}-\mathrm{C} 6\left(\mathrm{~K}_{\mathrm{D}}=43.9 \pm 4.0\right.$ $\mathrm{nM}$ and $107.3 \pm 15.9 \mathrm{nM}$, respectively, Fig. 2B). Similar results were obtained on HCC70 cells (Fig. 2C). Moreover, competition studies were performed to assess the specificity of binding (Fig. 2D). Binding of ${ }^{99 \mathrm{~m}} \mathrm{Tc}-\mathrm{A} 1$ and ${ }^{99 \mathrm{~m}} \mathrm{Tc}-\mathrm{C} 6$ to mesothelinpositive HCC70 cells was, respectively, 7.9- and 4.6-fold higher than that observed to mesothelin-negative MDA-MB-231 cells. Radiolabeled sdAb binding was displaced by a 200 -fold excess of unlabeled sdAb, with a significant 6-fold and 3.5-fold decrease in ${ }^{99 \mathrm{~m}} \mathrm{Tc}-\mathrm{A} 1$ and $99 \mathrm{~m} \mathrm{Tc}-\mathrm{C} 6$ binding, respectively. This result indicates that radiolabeled sdAbs retain their specific binding activity on mesothelin $(P<0.001)$.

\section{Blood Distribution Patterns and Stability In Vitro in Human Blood}

Similar distribution patterns were observed over time (Supplemental Fig. 2). Both sdAbs were predominantly localized in the plasma fraction $(63 \%-75 \%)$, where $-1.8 \pm 0.5$ for ${ }^{99 \mathrm{~m}} \mathrm{Tc}-\mathrm{A} 1$ and $-2.3 \pm 0.8$ for ${ }^{99 \mathrm{~m}} \mathrm{Tc}-\mathrm{C} 6$ (Supplemental Table 1).

they remained highly stable, with a radiochemical purity higher than $98 \%$ from 0 to $6 \mathrm{~h}$ (Supplemental Table 2).

\section{9mTc-A1 and 99mTc-C6 Affinity and Specificity for Mesothelin}

Western blot analysis indicated that mesothelin was expressed by HCC70 cells but not by MDA-MB-231 cells (Fig. 2A). Figure $2 \mathrm{~B}$ shows the specific binding of ${ }^{99 \mathrm{~m}} \mathrm{Tc}-\mathrm{A} 1$ and ${ }^{99 \mathrm{~m}} \mathrm{Tc}-\mathrm{C} 6$ on mesothelin recombinant protein. The affinity of ${ }^{99 \mathrm{~m} T c-A} 1$ for

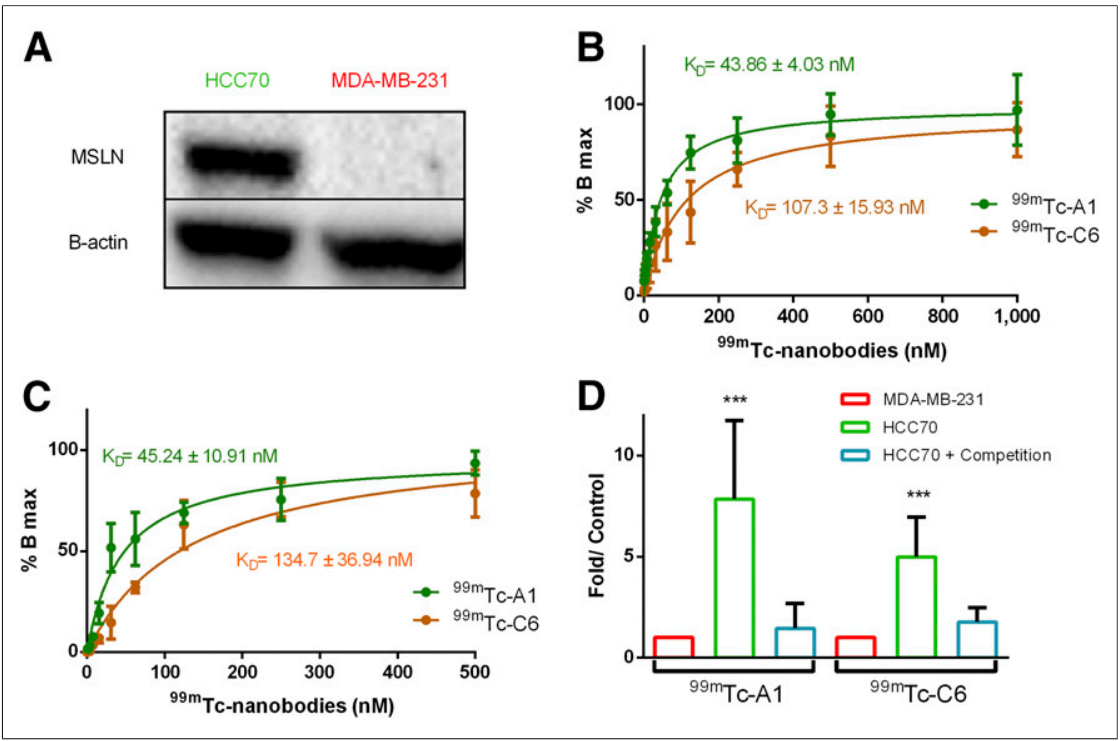

FIGURE 2. High-affinity and high-specificity binding of ${ }^{99 m T C}-A 1$ to mesothelin. (A) As determined by Western blot, HCC70 were mesothelin-positive whereas MDA-MB-231 were mesothelin-negative. (B) Saturation binding on human recombinant mesothelin (MSLN): $99 \mathrm{mTC}-\mathrm{A} 1$ and 99mTc-C6 $\mathrm{K}_{\mathrm{D}}$ was $44 \pm 4$ and $107 \pm 16 \mathrm{nM}$, respectively. (C) Saturation binding on HCC70 cells: ${ }^{99 \mathrm{~m} T C}-\mathrm{A} 1$ and ${ }^{99 \mathrm{mT}} \mathrm{Tc}-\mathrm{C} 6 \mathrm{~K}_{\mathrm{D}}$ was $45 \pm 11$ and $135 \pm 37 \mathrm{nM}$, respectively. (D) Binding of ${ }^{99 \mathrm{mTC}-\mathrm{A} 1}$ and ${ }^{99 m} \mathrm{Tc}-\mathrm{C} 6$ to $\mathrm{HCC} 70$ cells was significantly inhibited by 200 -fold excess of unlabeled A1 or C6 sdAb. ${ }^{\star \star \star} P<0.001$ vs. HCC70 + competition. Experiments were performed in triplicate.

\section{In Vivo Stability in Mouse Blood}

Radiochromatograms of ${ }^{99 \mathrm{~m}} \mathrm{Tc}-\mathrm{A} 1$ and ${ }^{99 \mathrm{~m}} \mathrm{Tc}-\mathrm{C} 6$, before and $2 \mathrm{~h}$ after injection, are shown in Figures 1C and 1D. A single peak corresponding to the radiolabeled sdAb was observed for both tracers. The absence of alternative radioactive products on the profiles confirmed the in vivo stability of ${ }^{99 \mathrm{~m}} \mathrm{Tc}-\mathrm{A} 1$ and ${ }^{99 \mathrm{~m}} \mathrm{Tc}-\mathrm{C} 6$, with radiochemical purities of $91.3 \% \pm 5.2 \%$ and $95.4 \% \pm 4.8 \%$, respectively.

\section{Immunohistochemistry}

Mesothelin expression was evaluated by immunohistochemistry on HCC70 and MDAMB-231 xenografts using a commercial antibody or A1 sdAb (Supplemental Fig. 3). In accordance with observations in cell cultures, HCC70 tumor xenografts expressed mesothelin whereas MDA-MB-231 did not.

\section{SPECT/CT Imaging}

Figure 3A shows sagittal, coronal, and transversal views of fused SPECT/CT images. ${ }^{99 \mathrm{~m}} \mathrm{Tc}-\mathrm{A} 1$ and ${ }^{99 \mathrm{~m}} \mathrm{Tc}-\mathrm{C} 6$ uptake in mesothelin-positive HCC70 tumors was readily identifiable, whereas a weak signal was observed with the irrelevant control sdAb in HCC70 tumors and with ${ }^{99 m} \mathrm{Tc}-$ A1 in mesothelin-negative MDA-MB-231 tumors. Interestingly, uptake of ${ }^{99 \mathrm{~m}} \mathrm{Tc}-\mathrm{C} 6$ in HCC70 tumors was visually lower than that of ${ }^{99 \mathrm{~m}} \mathrm{Tc}-\mathrm{A} 1$. Furthermore, liver accumulation was observed for ${ }^{99 \mathrm{~m}} \mathrm{Tc}-\mathrm{C} 6$ but not for ${ }^{99 \mathrm{~m}} \mathrm{Tc}-\mathrm{A} 1$. Nonspecific kidney elimination was observed in all groups. 


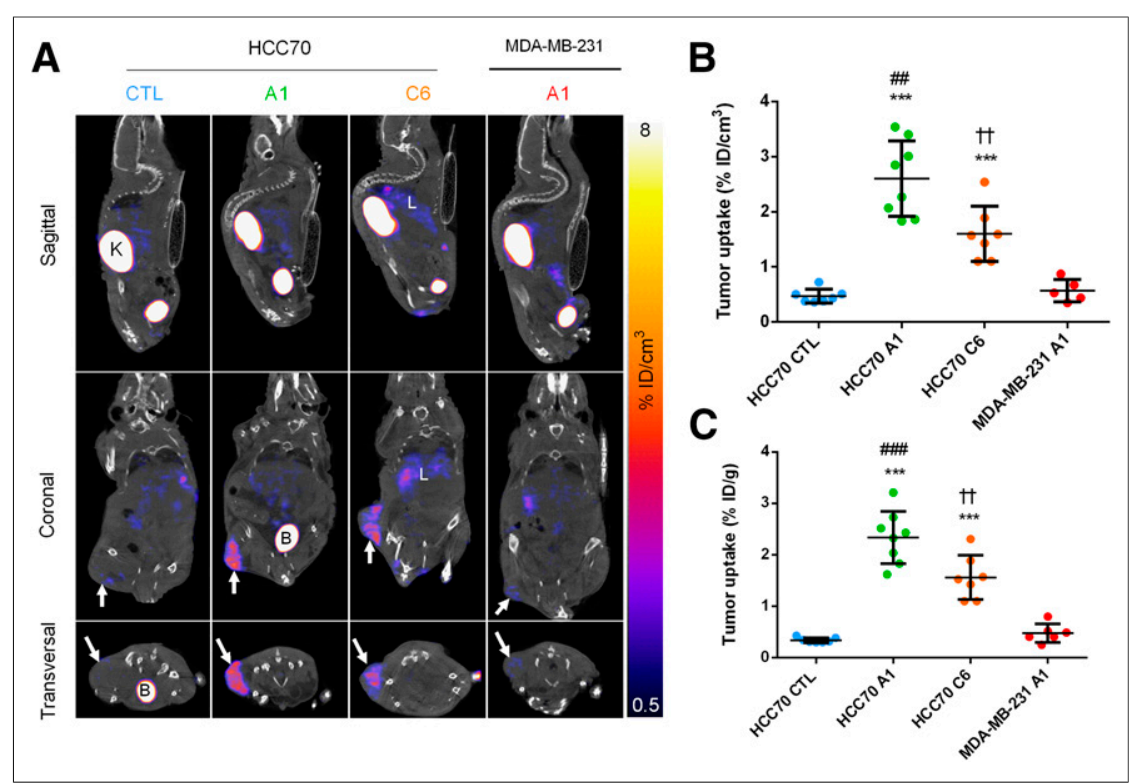

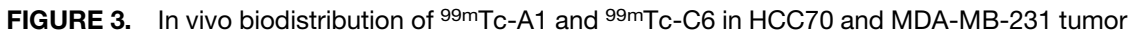
xenografts. (A) Representative sagittal, coronal, and transversal views of fused SPECT/CT images of HCC70 and MDA-MB-231 tumor-bearing mice $1 \mathrm{~h}$ after intravenous injection of ${ }^{99 \mathrm{mTC}-\mathrm{A} 1 \mathrm{or}}$

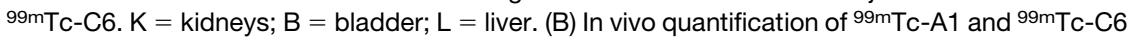
tumor uptake from SPECT images. (C) Ex vivo quantification of $99 \mathrm{mTc}-\mathrm{A} 1$ and $99 \mathrm{mTc}-\mathrm{C} 6$ tumor uptake from postmortem analysis. Results are expressed as $\% \mathrm{ID} / \mathrm{g}$ of tumor. ${ }^{\#} P<0.01 \mathrm{vs}$. MDAMB-231 A1. ${ }^{\# \# \# P<0.001 ~ v s . ~ M D A-M B-231 ~ A 1 . ~}{ }^{\star \star \star} P<0.001$ vs. HCC70 control sdAb. ${ }^{\dagger+} P<0.01$ vs. HCC-70 A1.

These observations were confirmed by image quantification showing that ${ }^{99 \mathrm{~m}} \mathrm{Tc}-\mathrm{A} 1$ activity was 5 -fold higher than ${ }^{99 \mathrm{~m}} \mathrm{Tc}-$ CTL activity in HCC70 tumor-bearing mice ( $2.6 \pm 0.7$ vs. $0.5 \pm$ $0.13 \% \mathrm{ID} / \mathrm{g}$, respectively, $P<0.01)$. In addition, ${ }^{99 \mathrm{~m}} \mathrm{Tc}-\mathrm{A} 1 \mathrm{up}-$ take in HCC70 tumors was 4-fold higher than that observed in MDA-MB-231 tumors $(0.6 \pm 0.2 \% \mathrm{ID} / \mathrm{g}, P<0.001)$ (Fig. 3B). HCC70 ${ }^{99 \mathrm{~m} T c-C 6}$ uptake $(1.4 \pm 0.3 \% \mathrm{ID} / \mathrm{g})$ was also significantly higher than that of ${ }^{99 \mathrm{~m}} \mathrm{Tc}-\mathrm{CTL}(P<0.001)$ but remained about 2 -fold lower than that of ${ }^{99 \mathrm{~m} T c-A 1}(P<0.01)$. These results were confirmed by ex vivo $\gamma$-well counting quantification (Fig. 3C). The agreement between results from in vivo and ex vivo quantification was further confirmed by linear regression analysis $\left(y=1.08 x+0.09, r^{2}=0.97, P<0.001\right)$ (Supplemental Fig. 4).

\section{Biodistribution of ${ }^{99 m T c-A 1}$ and $99 \mathrm{mTc}-\mathrm{C6}$}

The results from 2-h biodistribution studies after ${ }^{99 \mathrm{~m}} \mathrm{Tc}-\mathrm{A} 1$, ${ }^{99 \mathrm{~m}} \mathrm{Tc}-\mathrm{C} 6$, or ${ }^{99 \mathrm{~m}} \mathrm{Tc}-\mathrm{CTL}$ intravenous injection are summarized in Table 1 . High kidney activity $(>200 \% \mathrm{ID} / \mathrm{g})$ was observed for all sdAbs. ${ }^{99 m}$ Tc-A1 uptake was less than $1 \% \mathrm{ID} / \mathrm{g}$ for all investigated organs with the exception of kidney and tumor. In comparison, 99m Tc-C6 uptake was more than $1 \% \mathrm{ID} / \mathrm{g}$ in liver and significantly higher than that of ${ }^{99 \mathrm{~m}} \mathrm{Tc}-\mathrm{A} 1$ and ${ }^{99 \mathrm{~m}} \mathrm{Tc}-\mathrm{CTL}$ in stomach, liver, and intestine $(P<0.01)$. The blood activity of all 3 sdAbs was less than $0.5 \% \mathrm{ID} / \mathrm{g}$. T/B and T/M ratios were determined for each group. The T/B ratio of the HCC70-A1 group was 10 -fold higher than that of the HCC70-CTL group $(10.3 \pm 4.4$ vs. $1.1 \pm 0.7, P<0.001)$. Similarly, the T/M ratio of the HCC70-A1 group was 5-fold higher than that of the CTL group $(22.5 \pm 3.4$ vs. $4.0 \pm 1.8, P<0.001)$. The T/M and T/B ratios of the HCC70-C6 group were also found to be higher than those of the HCC70-CTL group $(P<0.01)$ but remained significantly lower than those of the HCC70-A1 group $(P<0.05$ for both ratios).

\section{In Vivo Competition Study}

The in vivo coinjection of a 150 -fold excess of unlabeled A1 induced an approximately 7 -fold decrease in ${ }^{99 \mathrm{~m}} \mathrm{Tc}-\mathrm{A} 1$ uptake in HCC70 tumors as determined by SPECT image quantification $(0.6 \pm 0.2$ $\% \mathrm{ID} / \mathrm{g}$ for $\mathrm{HCC} 70-\mathrm{A} 1+$ competition vs. $4.8 \pm 0.8 \% \mathrm{ID} / \mathrm{g}$ for HCC70-A1 alone, $P<0.01$, Fig. 4). Ex vivo $\gamma$-well counting further confirmed this finding $(0.5 \pm 0.1$ $\% \mathrm{ID} / \mathrm{g}$ with competitor vs. $4.2 \pm 0.8 \% \mathrm{ID} / \mathrm{g}$ without, $P<0.01$ ) (Table 2). With the exception of kidney, ${ }^{99 \mathrm{~m}} \mathrm{Tc}-\mathrm{A} 1$ uptake in all other investigated organs did not significantly change. Consequently, a significant decrease was observed in T/B and T/M ratios ( $P<0.01$ for both).

\section{DISCUSSION}

Most cases of TNBC have an aggressive clinical course characterized by a higher recurrence rate, more distant metastases, and an overall lower survival than other forms of breast cancer (1). TNBCs are treated with chemotherapy or radiation therapy. However, because some are chemotherapy-resistant, other therapies, such as immunotherapy, are being evaluated (20).

Potential targets have been identified, including mesothelin $(2,3)$. Mesothelin is a $40-\mathrm{kDa}$ glycosylphosphatidylinisotolanchored membrane glycoprotein with limited normal-tissue expression and frequent overexpression in most types of aggressive cancer, such as pancreatic cancer, ovarian adenocarcinoma, mesothelioma, and TNBC $(5,7)$. Several therapies targeting mesothelinexpressing tumors have been developed and are currently undergoing clinical translation (15). Preclinical studies using RG7787, a recombinant immunotoxin, in combination with chemotherapy showed complete remission of mesothelin-expressing tumor xenografts in mice (21). Phase I clinical trials of RG7787 for treatment of mesothelioma have opened (22). Moreover, on the basis of studies showing that mesothelin could elicit a CD8-positive T-cell response in patients, tumor vaccines are under clinical investigations (23).

Patients with mesothelin-expressing tumors can be identified using biopsy and blood testing with the serum mesothelin-related peptide $(16,24)$. However, discordance in the expression of tumor markers is often observed between the primary tumor and the metastases, which are not always accessible to biopsy. In addition, this marker is not increased in pancreatic cancer despite an overexpression of the mesothelin-membrane form (17). By allowing noninvasive tumoral phenotyping, nuclear imaging might help to overcome the limitations of biopsies and blood testing mentioned above.

The objective of the present study was to perform the in vivo nuclear imaging of TNBC xenografts with ${ }^{99 \mathrm{~m}} \mathrm{Tc}-\mathrm{A} 1$ and ${ }^{99 \mathrm{~m}} \mathrm{Tc}-$ C6, two antimesothelin sdAbs, using the two TNBC cell lines HCC70 and MDA-MB-231. Mesothelin expression was observed on HCC70 cells but not on MDA-MB-231 cells, which were 
TABLE 1

Biodistribution of ${ }^{99 m T c-A 1}$ and ${ }^{99 m T c-C 6}$ in Athymic Nude Mice Bearing HCC70 or MDA-MB-231 Xenografts

\begin{tabular}{|c|c|c|c|c|}
\hline Target & HCC70 CTL $(n=7)$ & HCC70 A1 $(n=8)$ & HCC70 C6 $(n=7)$ & MDA-MB-231 A1 $(n=6)$ \\
\hline Brain & $0.01 \pm 0.01$ & $0.01 \pm 0.00$ & $0.01 \pm 0.00$ & $0.01 \pm 0.00$ \\
\hline Stomach & $0.35 \pm 0.14$ & $0.42 \pm 0.06$ & $0.67 \pm 0.24^{\star \dagger}$ & $0.43 \pm 0.07$ \\
\hline Intestine & $0.29 \pm 0.10$ & $0.36 \pm 0.08$ & $0.58 \pm 0.30^{\star}+$ & $0.30 \pm 0.08$ \\
\hline Liver & $0.66 \pm 0.15$ & $0.74 \pm 0.18^{\ddagger}$ & $1,25 \pm 0.19^{\star}+$ & $0.58 \pm 0.06$ \\
\hline Pancreas & $0.16 \pm 0.05$ & $0.27 \pm 0.07^{\star \ddagger}$ & $0.22 \pm 0.03$ & $0.18 \pm 0.03$ \\
\hline Heart & $0.24 \pm 0.11$ & $0.23 \pm 0.04^{\S}$ & $0.20 \pm 0.04$ & $0.15 \pm 0.05$ \\
\hline Lungs & $0.68 \pm 0.24$ & $0.61 \pm 0.10$ & $0.80 \pm 0.11$ & $0.56 \pm 0.27$ \\
\hline Kidney & $264.56 \pm 31.77$ & $268.81 \pm 16.49^{\S}$ & $255.21 \pm 41.80$ & $233.21 \pm 13.14$ \\
\hline Bones & $0.22 \pm 0.07$ & $0.22 \pm 0.02^{\ddagger}$ & $0.21 \pm 0.04$ & $0.16 \pm 0.01$ \\
\hline Ovaries & $0.42 \pm 0.19$ & $0.50 \pm 0.14$ & $0.61 \pm 0.09$ & $0.44 \pm 0.18$ \\
\hline Lymph nodes & $0.50 \pm 0.35$ & $0.44 \pm 0.16$ & $0.42 \pm 0.04$ & $0.33 \pm 0.06$ \\
\hline Blood & $0.42 \pm 0.24$ & $0.25 \pm 0.10$ & $0.28 \pm 0.07$ & $0.19 \pm 0.10$ \\
\hline Muscle & $0.10 \pm 0.04$ & $0.10 \pm 0.02$ & $0.09 \pm 0.02$ & $0.09 \pm 0.02$ \\
\hline Tumor & $0.34 \pm 0.05$ & $2.34 \pm 0.36 \| \rrbracket$ & $1.56 \pm 0.43^{\| \dagger}$ & $0.48 \pm 0.18$ \\
\hline $\mathrm{T} / \mathrm{B}$ & $1.05 \pm 0.69$ & $10.32 \pm 4.43^{\S} \|$ & $5.66 \pm 1.12^{\star \#}$ & $3.09 \pm 2.39$ \\
\hline $\mathrm{T} / \mathrm{M}$ & $3.99 \pm 1.78$ & $22.46 \pm 3.43 \| \rrbracket$ & $17.18 \pm 3.60^{\star \#}$ & $5.26 \pm 1.40$ \\
\hline 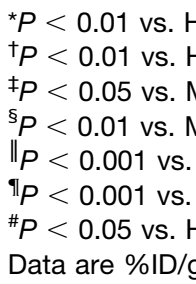 & $\begin{array}{l}\text { CTL. } \\
\text {-A1. } \\
\text { IB-231 A1. } \\
\text { IB-231 A1. } \\
\text { 0-CTL. } \\
\text { MB-231 A1. } \\
\text {-A1. } \\
3 \text { and T/M ratios. }\end{array}$ & & & \\
\hline
\end{tabular}

therefore used as a negative control. ${ }^{99 \mathrm{~m}} \mathrm{Tc}-\mathrm{A} 1$ exhibited a high affinity for mesothelin $\left(\mathrm{K}_{\mathrm{D}}=43 \mathrm{nM}\right)$, as demonstrated in vitro on recombinant mesothelin human protein and HCC70 cells. In vitro competition experiments on HCC70 cells confirmed the ${ }^{99 \mathrm{~m} T c-A 1}$ binding specificity. In accordance with the results of Prantner et al.
(18) using unlabeled compounds, the affinity of $99 \mathrm{~m} \mathrm{Tc}-\mathrm{C} 6$ for human recombinant mesothelin was found to be 3 -fold lower than that of ${ }^{99 \mathrm{~m}} \mathrm{Tc}-\mathrm{A} 1$, thereby indicating the suitability of the radiolabeling method. Both radiotracers remained stable over time after in vitro incubation with human blood and in vivo injection into mice. Moreover, ${ }^{99 \mathrm{~m}} \mathrm{Tc}-\mathrm{A} 1$ and ${ }^{99 \mathrm{~m}} \mathrm{Tc}-\mathrm{C} 6$ remained mostly in the plasma fraction, thereby allowing good in vivo bioavailability. ${ }^{99 \mathrm{~m} T c-A 1}$ and ${ }^{99 m}$ Tc-C6 both enabled the noninvasive visualization of mesothelin-positive tumors by SPECT imaging. High accumulation of ${ }^{99 \mathrm{~m}} \mathrm{Tc}-\mathrm{A} 1$ and ${ }^{99 \mathrm{~m} T c-C 6}$ was observed in mesothelinpositive HCC70 tumors, whereas no signal was found in mesothelin-negative MDA-MB-231 tumors. However, the signal of ${ }^{99 \mathrm{~m}} \mathrm{Tc}-\mathrm{A} 1$ in HCC70 tumors was higher than that of ${ }^{99 m}$ Tc-C6. SPECT image quantification further confirmed these results, with a 5-fold higher ${ }^{99 \mathrm{~m}} \mathrm{Tc}-\mathrm{A} 1$ uptake in HCC70 tumors than in MDAMB-231 tumors. Moreover, the in vivo competition study demonstrated the specificity of ${ }^{99 \mathrm{~m}} \mathrm{Tc}-\mathrm{A} 1$ binding to mesothelin. Renal accumulation was observed with both tracers, in accordance with the general pattern of sdAb biodistribution (25). In fact, 
TABLE 2

Effect of Competitor on 99mTc-A1 Biodistribution in Athymic Nude Mice Bearing HCC70 Xenografts

\begin{tabular}{lcc}
\hline \multicolumn{1}{c}{ Target } & $\begin{array}{c}\text { HCC70 A1 } \\
(n=5)\end{array}$ & $\begin{array}{c}\text { HCC70 A1 }+ \text { competition } \\
(n=5)\end{array}$ \\
\hline Brain & $0.01 \pm 0.00$ & $0.01 \pm 0.00$ \\
\hline Stomach & $0.59 \pm 0.15$ & $0.49 \pm 0.23$ \\
\hline Intestine & $0.52 \pm 0.30$ & $0.42 \pm 0.28$ \\
\hline Liver & $0.95 \pm 0.24$ & $0.72 \pm 0.33$ \\
\hline Pancreas & $0.28 \pm 0.03$ & $0.19 \pm 0.06$ \\
\hline Heart & $0.21 \pm 0.08$ & $0.22 \pm 0.08$ \\
\hline Lungs & $0.79 \pm 0.25$ & $0.65 \pm 0.29$ \\
\hline Kidney & $270.12 \pm 15.70^{*}$ & $180.76 \pm 28.69$ \\
\hline Bones & $0.23 \pm 0.07$ & $0.28 \pm 0.15$ \\
\hline Ovaries & $0.67 \pm 0.19$ & $0.50 \pm 0.13$ \\
\hline Lymph nodes & $0.63 \pm 0.11$ & $0.56 \pm 0.13$ \\
\hline Blood & $0.30 \pm 0.13$ & $0.25 \pm 0.14$ \\
\hline Muscle & $0.14 \pm 0.04$ & $0.15 \pm 0.05$ \\
\hline Tumor & $4.23 \pm 0.83^{\dagger}$ & $0.54 \pm 0.10$ \\
\hline T/B & $14.49 \pm 6.43^{\dagger}$ & $3.01 \pm 1.66$ \\
\hline T/M & $35.26 \pm 11.73^{\dagger}$ & $3.78 \pm 1.20$ \\
\hline
\end{tabular}

${ }^{\star} P<0.05$ vs. HCC70 A1 + competition.

${ }^{\dagger} P<0.01$ vs. HCC70 A1 + competition.

Data are $\% \mathrm{ID} / \mathrm{g}$ or $\mathrm{T} / \mathrm{B}$ and $\mathrm{T} / \mathrm{M}$ ratio.

most sdAbs are eliminated through the kidneys, and reuptake by the megalin-cubulin complex is responsible for their renal retention. In addition to tumor, kidney was also shown to have decreased ${ }^{99 \mathrm{~m}} \mathrm{Tc}-$ A1 retention by the competition studies, as might be explained by the saturation of the megalin-cubulin complex by the competitor. Such saturation of this complex has been applied by other groups using succinylated gelatin, a plasma substitute, resulting in a significant $40 \%-50 \%$ decrease in kidney retention of the evaluated sdAb (26). No signal was observed on in vivo SPECT images after ${ }^{99 m}$ TcA1 injection with the exception of tumor, kidney, and bladder, most likely as a result of, first, weak mesothelin expression limited to the pericardium, pleura, and peritoneum and, second, A1 affinity for human mesothelin. Interestingly, mild-intensity signals were also observed in liver and intestine after ${ }^{99 \mathrm{~m}} \mathrm{Tc}-\mathrm{C} 6$ injection, suggesting that the liver is involved in ${ }^{99 \mathrm{~m}} \mathrm{Tc}-\mathrm{C} 6$ elimination. Monoclonal antibodies radiolabeled with ${ }^{64} \mathrm{Cu}$ or ${ }^{89} \mathrm{Zr}$ have recently allowed the detection of mesothelin-expressing tumors in mouse models of xenograft pancreatic tumors $(27,28)$. Nevertheless, the hepatic elimination and slow blood clearance of these radiolabeled monoclonal antibodies represent major limitations. The smaller size of sdAbbased imaging agents allows fast blood clearance and image acquisition with high target-to-background ratios as early as $1 \mathrm{~h}$ after

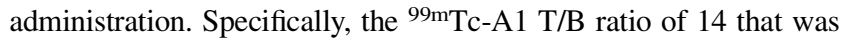
observed in the present study at $2 \mathrm{~h}$ after injection compares favorably with the T/B ratio of $1-4$ that was previously observed at $24 \mathrm{~h}$ after injection for ${ }^{64} \mathrm{Cu}$ and ${ }^{89} \mathrm{Zr}$-labeled antibodies $(27,28)$.

Because $20 \%$ of women with breast cancer will develop distant metastases within $5 \mathrm{y}$ of diagnosis, an ideal TNBC imaging agent should demonstrate high target-to-background ratios not only at the primary tumor site but also in pulmonary, hepatic, and bone lesions since these are the most frequent metastatic sites for TNBC. In the present study, minimal nonspecific uptake was observed in those organs with ${ }^{99 \mathrm{~m}} \mathrm{Tc}-\mathrm{A} 1$ but not with ${ }^{99 \mathrm{~m}} \mathrm{Tc}-\mathrm{C} 6$. Taken together with the higher affinity and higher absolute tumor uptake of ${ }^{99 \mathrm{~m}} \mathrm{Tc}-\mathrm{A} 1$, this additional result suggests that it would be better suited for metastasis imaging. We will therefore conduct further studies to evaluate the potential of ${ }^{99 \mathrm{~m}} \mathrm{Tc}-\mathrm{A} 1$ for the detection of breast cancer metastasis in mice. Although HCC70 cells share features of TNBC, few data on their metastatic abilities in mice are available. Other TNBC cells might therefore also be used.

\section{CONCLUSION}

The identification of mesothelin-expressing metastases would allow selection of patients who might benefit from mesothelintargeted therapies. Two antimesothelin sdAbs were evaluated for their ability to detect mesothelin-expressing tumors in vivo. The results indicated that ${ }^{99 \mathrm{~m}} \mathrm{Tc}-\mathrm{A} 1$ is a promising tracer for the detection of mesothelin-expressing tumors. Further development of ${ }^{99 \mathrm{~m}} \mathrm{Tc}-\mathrm{A} 1$ will include 1,4,7,10-tetraazacyclododecane-1,4,7,10-tetraacetic acid chelation chemistry to allow either ${ }^{68} \mathrm{Ga}$ or ${ }^{177} \mathrm{Lu}$ radiolabeling for diagnosis and therapy, additional chemical engineering to minimize renal uptake, and additional characterizations such as internalization and tumor retention.

\section{DISCLOSURE}

This work was partly funded by grant ANR-11-INBS-0006 from France Life Imaging. No other potential conflict of interest relevant to this article was reported.

\section{ACKNOWLEDGMENT}

We thank Dr. Annie Molla (Université Grenoble Alpes, INSERM, CNRS, IAB, Grenoble), who kindly provided the HCC70 cell line.

\section{REFERENCES}

1. Dent R, Trudeau M, Pritchard KI, et al. Triple-negative breast cancer: clinical features and patterns of recurrence. Clin Cancer Res. 2007;13:4429-4434.

2. Crown J, O'Shaughnessy J, Gullo G. Emerging targeted therapies in triple-negative breast cancer. Ann Oncol. 2012;23:vi56-vi65.

3. André F, Zielinski CC. Optimal strategies for the treatment of metastatic triplenegative breast cancer with currently approved agents. Ann Oncol. 2012;23: vi46-vi51.

4. Chang K, Pastan I. Molecular cloning of mesothelin, a differentiation antigen present on mesothelium, mesotheliomas, and ovarian cancers. Proc Natl Acad Sci USA. 1996;93:136-140.

5. Ordóñez NG. Application of mesothelin immunostaining in tumor diagnosis. Am J Surg Pathol. 2003;27:1418-1428.

6. Parinyanitikul N, Blumenschein GR, Wu Y, et al. Mesothelin expression and survival outcomes in triple receptor negative breast cancer. Clin Breast Cancer. 2013;13:378-384

7. Tchou J, Wang L-C, Selven B, et al. Mesothelin, a novel immunotherapy target for triple negative breast cancer. Breast Cancer Res Treat. 2012;133:799-804.

8. Bera TK, Pastan I. Mesothelin is not required for normal mouse development or reproduction. Mol Cell Biol. 2000;20:2902-2906.

9. Tang Z, Qian M, Ho M. The role of mesothelin in tumor progression and targeted therapy. Anticancer Agents Med Chem. 2013;13:276-280.

10. Kachala SS, Bograd AJ, Villena-Vargas J, et al. Mesothelin overexpression is a marker of tumor aggressiveness and is associated with reduced recurrence-free and overall survival in early-stage lung adenocarcinoma. Clin Cancer Res. 2014; 20:1020-1028. 
11. Cheng W-F, Huang C-Y, Chang M-C, et al. High mesothelin correlates with chemoresistance and poor survival in epithelial ovarian carcinoma. Br J Cancer. 2009; 100:1144-1153.

12. Wang L, Niu Z, Zhang L, et al. Clinicopathological significance of mesothelin expression in invasive breast cancer. J Int Med Res. 2012;40:909-916.

13. Tozbikian G, Brogi E, Kadota K, et al. Mesothelin expression in triple negative breast carcinomas correlates significantly with basal-like phenotype, distant metastases and decreased survival. PLoS One. 2014;9:e114900.

14. Li YR, Xian RR, Ziober A, et al. Mesothelin expression is associated with poor outcomes in breast cancer. Breast Cancer Res Treat. 2014;147:675-684

15. Hassan R, Ho M. Mesothelin targeted cancer immunotherapy. Eur J Cancer. 2008;44:46-53.

16. Hassan R. Detection and quantitation of serum mesothelin, a tumor marker for patients with mesothelioma and ovarian cancer. Clin Cancer Res. 2006;12:447-453.

17. Sharon E, Zhang J, Hollevoet K, et al. Serum mesothelin and megakaryocyte potentiating factor in pancreatic and biliary cancers. Clin Chem Lab Med. 2012;50:721-725.

18. Prantner AM, Turini M, Kerfelec B, et al. Anti-mesothelin nanobodies for both conventional and nanoparticle-based biomedical applications. J Biomed Nanotechnol. 2015;11:1201-1212.

19. Dumas LS, Briand F, Clerc R, et al. Evaluation of antiatherogenic properties of ezetimibe using ${ }^{3} \mathrm{H}$-labeled low-density-lipoprotein cholesterol and ${ }^{99 \mathrm{~m}} \mathrm{Tc}-\mathrm{cAbV}$ CAM1-5 SPECT in ApoE ${ }^{-/-}$mice fed the Paigen diet. J Nucl Med. 2017;58: 1088-1093.

20. Anders CK, Carey LA. Biology, metastatic patterns, and treatment of patients with triple-negative breast cancer. Clin Breast Cancer. 2009;9(suppl):S73-S81.
21. Bauss F, Lechmann M, Krippendorff B-F, et al. Characterization of a re-engineered, mesothelin-targeted Pseudomonas exotoxin fusion protein for lung cancer therapy. Mol Oncol. 2016;10:1317-1329.

22. Hassan R, Thomas A, Alewine C, Le DT, Jaffee EM, Pastan I. Mesothelin immunotherapy for cancer: ready for prime time? J Clin Oncol. 2016;34:41714179.

23. Le DT, Brockstedt DG, Nir-Paz R, et al. A live-attenuated Listeria vaccine (ANZ-100) and a live-attenuated Listeria vaccine expressing mesothelin (CRS207) for advanced cancers: phase I studies of safety and immune induction. Clin Cancer Res. 2012;18:858-868.

24. Franko A, Dolzan V, Kovac V, Arneric N, Dodic-Fikfak M. Soluble mesothelinrelated peptides levels in patients with malignant mesothelioma. Dis Markers. 2012;32:123-131.

25. Gainkam LO, Caveliers V, Devoogdt N, et al. Localization, mechanism and reduction of renal retention of technetium- $99 \mathrm{~m}$ labeled epidermal growth factor receptor-specific nanobody in mice. Contrast Media Mol Imaging. 2011;6:8592.

26. D'Huyvetter M, Vincke C, Xavier C, et al. Targeted radionuclide therapy with a ${ }^{177}$ Lu-labeled anti-HER2 nanobody. Theranostics. 2014;4:708-720.

27. Kobayashi K, Sasaki T, Takenaka F, et al. A novel PET imaging using ${ }^{64} \mathrm{Cu}-$ labeled monoclonal antibody against mesothelin commonly expressed on cancer cells. J Immunol Res. 2015;2015:268172.

28. ter Weele EJ, van Scheltinga AGT, Kosterink JG, et al. Imaging the distribution of an antibody-drug conjugate constituent targeting mesothelin with ${ }^{89} \mathrm{Zr}$ and IRDye $800 \mathrm{CW}$ in mice bearing human pancreatic tumor xenografts. Oncotarget. 2015;6:42081. 